\title{
Optically Transparent Membrane Based on Bacterial Cellulose/Polycaprolactone
}

\author{
H. S. Barud , S. J. L. Ribeiro \\ Institute of Chemistry, São Paulo State University - UNESP, Brazil \\ C. L. P Carone , R. Ligabue, Sandra Einloft \\ Laboratório de Organometálicos e Resinas - LOR, PUC-RS, Porto Alegre, RS, Brazil \\ P. V. S. Queiroz , A. P. B. Borges \\ Department of Veterinary, Federal University of Viçosa - UFV, Brazil \\ V. D. Jahno \\ Institute of Exact Sciences and Technology, FEEVALE, Brazil
}

\begin{abstract}
Optically transparent membranes from bacterial cellulose (BC)/polycaprolactone (PCL) have been prepared by impregnation of PCL acetone solution into dried BC membranes. UV-Vis measurements showed an increase on transparency in BC/PCL membrane when compared with pristine BC. The good transparency of the BC/PCL can be related to the presence of BC nanofibers associated with deposit of PCL nano-sized spherulites which are smaller than the wavelength of visible light and practically free of light scattering. XRD results show that cellulose type I structure is preserved inside the BC/PCL membrane, while the mechanical properties suggested indicated that PCL acts as a plasticizer for the BC membrane. The novel BC/PCL membrane could be used for preparation of fully biocompatible flexible display and biodegradable food packaging.
\end{abstract}

Keywords: Bacterial cellulose, polycaprolactone, transparent membrane.

\section{Introduction}

In the last years bacterial cellulose (BC)-based materials have been largely investigated aiming the utilization in opto-electronic devices $^{[1-3]}$. The main applications of these novel materials include $\mathrm{BC}$ membranes as substrates for flexible organic lighting emission $(\text { FOLED })^{[4]}$, optically transparent BC-composites ${ }^{[5]}$ and matrix for electronic papers ${ }^{[6]}$.

Bacterial cellulose membranes are produced by Gluconacetobacter xylinus strain in carbohydrate rich culture medium. The obtained BC hydrogels presents 3-D cellulose network nanofiber, high crystallinity (60-90\%), high mechanical strength and full biocompatibility ${ }^{[7]}$. Cellulose nanofibers are considered highly effective reinforcements to produce high-performance optically composites that have mechanical properties similar to those of metals ${ }^{[1]}$. In fact, $\mathrm{BC}$ nanofibers are practically free of light scattering, showing also small thermal expansion coefficient, which is an important property for fillers in optoelectronic devices ${ }^{[1-2]}$.

Recent efforts have been devoted in the preparation of optically transparent BC composites associated with other biodegradable polymers. Transparent biocompatible nanocomposite was prepared by adding bacterial cellulose membrane into poly (L-lactic acid) (PLLA) matrix ${ }^{[8]}$.

New transparent nanocomposites based on different chitosan matrices and bacterial cellulose were prepared by a fully green procedure by casting a water based suspension of chitosan and bacterial cellulose nanofibrils. The BC-chitosan composites were highly transparent, flexible and displayed better mechanical properties than the corresponding unfilled chitosan films ${ }^{[9]}$.

A biocompatible polymeric composite $\mathrm{PHB} / \mathrm{BC}$ was prepared by incorporating bacterial cellulose (BC) into poly (3-hydroxybutyrate) (PHB) matrix. The transparency of the
PHB/BC nanocomposite was higher than pure BC membrane. BC also improved the thermal stability of PHB in the nanocomposite film ${ }^{[10]}$.

Bacterial cellulose-poly (vinyl alcohol) nanocomposites were prepared by an in-situ process. The addition of a small amount of PVA turned the BC membranes in an optical transparent material with excellent mechanical properties ${ }^{[11]}$.

Polycaprolactone (PCL) is a hydrophobic, semi-crystalline polymer; its crystallinity tends to decrease with the increase of the molecular weight. The good solubility of PCL in organic solvents, its low melting point $\left(59-64{ }^{\circ} \mathrm{C}\right)$ and the exceptional blend-compatibility has stimulated an extensive research of the potential application of this material in the biomedical field ${ }^{[12]}$.

The goal of this work was the preparation and characterization of a new optically transparent membrane based on dried bacterial cellulose and polycaprolactone (PCL).

\section{Experimental Section}

Bacterial cellulose was prepared according to a method described recently ${ }^{[13]}$. Polycaprolactone diol ( $M M=2000$, Aldrich) was used as received. The dried BC membranes $\left(6 \times 6 \mathrm{~cm}^{2}\right.$, $12 \mu \mathrm{m}$ thick) were previously swollen for 48 hours in acetone. Acetone-swollen BC membrane was soaked in $25 \mathrm{~mL}$ of $3 \%$ (w/v) PCL acetone solution during 72 hours. After this, BC/PCL membranes were washed several times with acetone to remove the excess of PCL. They were dried at $40{ }^{\circ} \mathrm{C}$ for 12 hours in Teflon plates. The PCL content in the nanocomposite was $12.0 \%(\mathrm{w} / \mathrm{w})$, determined by gravimetric measurements. Scanning electron microscopy (SEM) images were obtained in a Field Emission Scanning Electron Microscope JEOL JSM - 7500F. Samples 
were coated with tick carbon layer. XRD patterns were obtained in a Siemens Kristalloflex diffractometer using nickel filtered $\mathrm{Cu}$ $\mathrm{K} \alpha$ radiation, step pass of $0.02^{\circ}$ and a step time of 3 seconds, from 4 to $50^{\circ}(2 \theta$ angle). Thermal degradation analysis was performed using a Q600 SDT (TA Instruments). The samples were heated from $25-600{ }^{\circ} \mathrm{C}$ of temperature with open platinum pans under dynamic nitrogen atmosphere and at heating rate of $20{ }^{\circ} \mathrm{C} \mathrm{min}$. The mechanical measurements were performed with a Dynamic

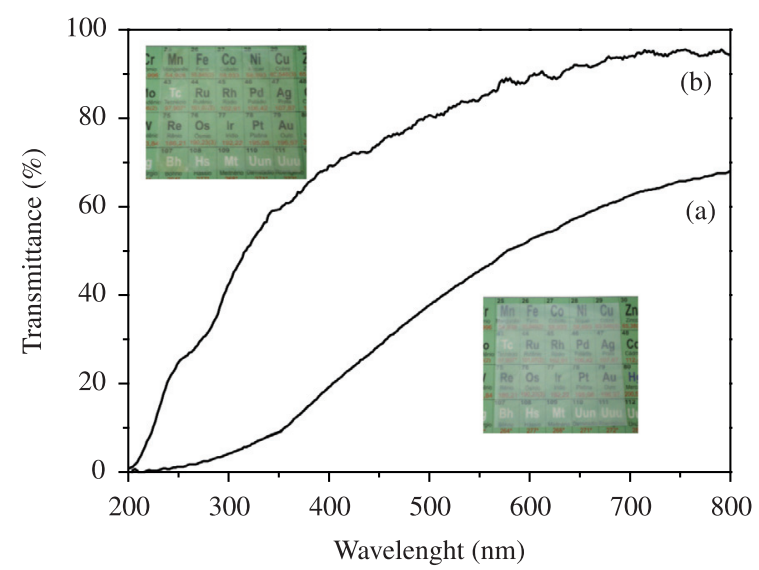

Figure 1. Optical transmission spectra for the: a) BC membrane, b) BC/PCL membrane. Inset images of the pure $\mathrm{BC}$ membrane (below) and transparent BC/PCL membrane (up).

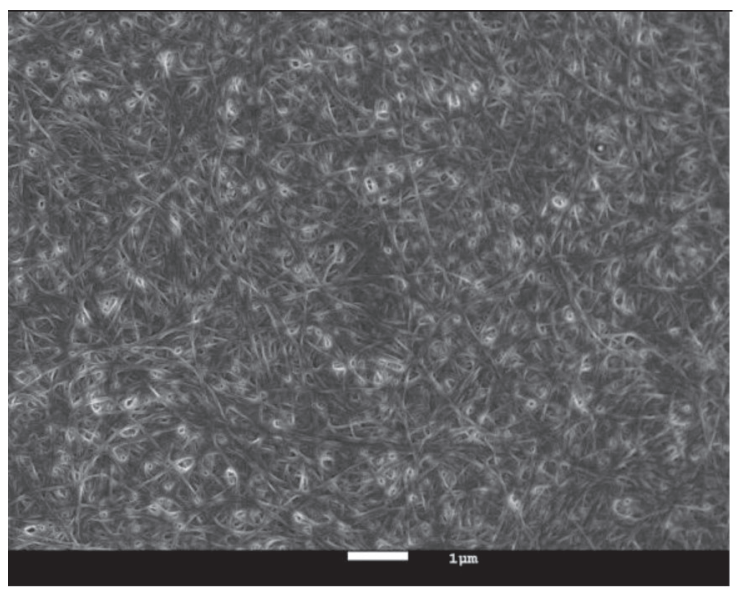

(a)

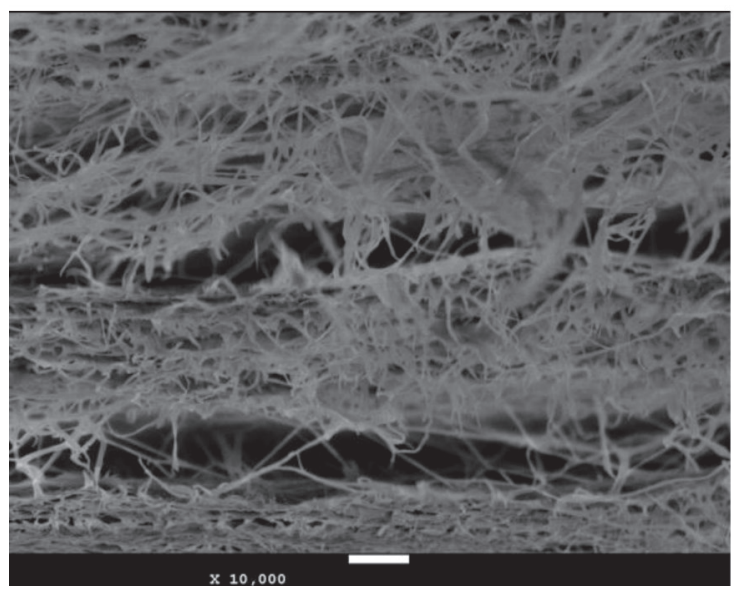

(c)
Mechanical Analyzer (DMA) Q 800 (TA Instruments) equipped with a film tension clamp at a temperature of $27^{\circ} \mathrm{C}$. The specimens were cut in dimensions of $5.50 \mathrm{~mm} \times 6.20 \mathrm{~mm} \times 0.02 \mathrm{~mm}$ (length $\times$ width $\times$ thickness). The device was previously calibrated and a total of 4 measurements for each sample were made in order to ensure the reproducibility of the results.

\section{Results and Discussion}

The Figure 1 shows the optical transmission spectra for pristine $\mathrm{BC}$ membrane and BC/PCL biocomposite. Pure PCL material does not form stable films.

Pristine BC membrane, Figure 1a (inset), is a semi-transparent material presenting an average transmittance at $550 \mathrm{~nm}$ of around $45 \%{ }^{[4]}$. The light transmittance of BC/PCL membrane is $84 \%$ at $550 \mathrm{~nm}$ (Figure 1b). The high transmittance is due primarily to the lateral size of the reinforcing elements; the light scattering is avoided by BC nanofibers which are smaller than the wavelength of light ${ }^{[1]}$. This increase on the transparency in the visible range of the electromagnetic spectrum is an important characteristic for the fabrication of flexible OLEDs ${ }^{[1-4]}$.

SEM image of the BC membrane surface, Figure $2 \mathrm{a}$, reveals a 3-D fibrilar organization consisting of an ultrafine cellulose nanofibers network named "nanocelluloses". The micrograph of the surface of BC/PCL membrane, Figure 2b, show BC nanofibrills covered by PCL, resulting in a smooth surface morphology, suggesting a good interaction between the two phases.

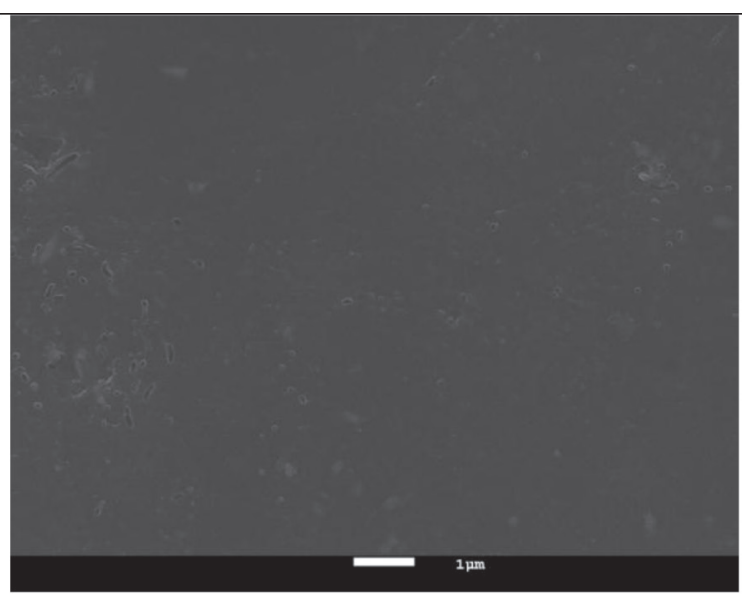

(b)

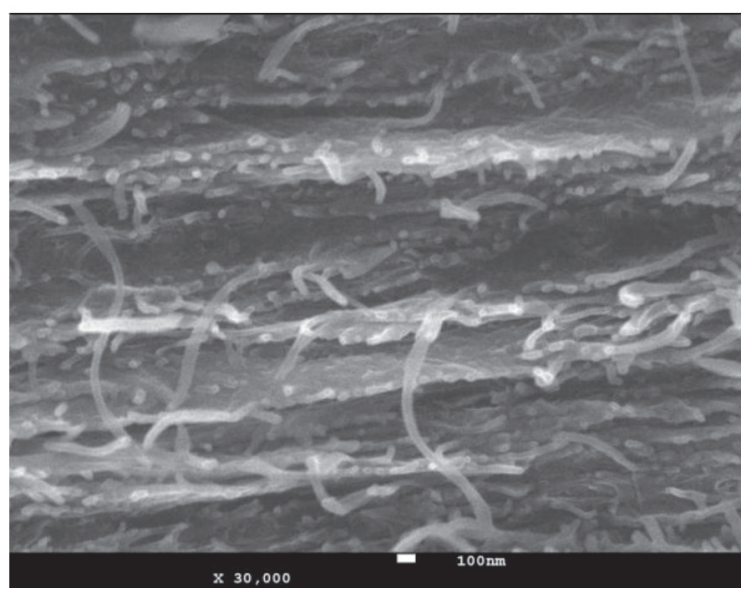

(d)

Figure 2. SEM images of: a) BC membrane surface, b) BC/PCL membrane, c) Cross-section image of BC membrane and d) Cross-section image of BC/PCL membrane. 


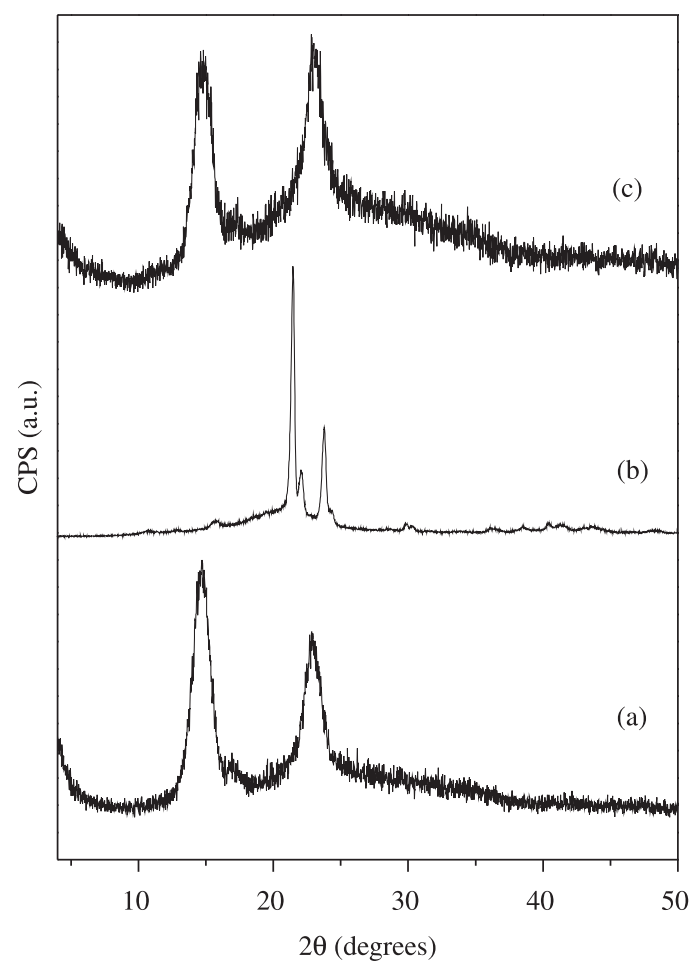

Figure 3. XRD Analyses of: a) BC membrane; b) PCL powder; c) BC/PCL membrane.

The cross-section image of pristine $\mathrm{BC}$ is shown in Figure 2c. A plate-like material is clearly observed with numerous sheets forming a network of nanofibrills. SEM images for BC/PCL, Figure $2 \mathrm{~d}$ suggest that PCL molecules completely filled the porous between BC nanofibrills. The image reveals that PCL is deposited as nano-sized spherulites. The improved transparency of the membranes can be associated with two aspects, the first one is due to the presence of $\mathrm{BC}$ nanofibers, as discussed above and the other aspect refers to the presence of PCL like nano-sized spherulite, which are smaller than the wavelength of visible range ${ }^{[10]}$.

Analysing the XRD patterns, it was possible to observe a broad diffraction peaks at $15^{\circ}$ and $22.5^{\circ}$ for the pure BC membrane, Figure $3 \mathrm{a}$, which are typical of cellulose type I. These peaks are assigned to the characteristic interplane distances of cellulose $1 \alpha$ and $1 \beta$ phases $^{[14]}$. The diffraction pattern obtained for the PCL is characteristic of the semi-crystalline polymer with two diffraction peaks, around 21.5 and 23.5 degrees. Moreover, the peaks were sharp and indicated that the samples were highly crystalline materials ${ }^{[15]}$. Cellulose type I patterns were observed for BC/PCL membrane, Figure $3 \mathrm{c}$, confirming that $\mathrm{BC}$ structure is preserved during preparation. Meanwhile, a difference can be observed in the relative intensity of the $\mathrm{BC}$ peaks, suggesting a change in the orientation of the cellulose fibres in the presence of PCL ${ }^{[11]}$.

The TGA curve obtained for pure BC membrane (Figure 4a) shows two events of weight loss. The first gradual one involving $5 \%$ of mass loss occurred from room temperature up to $150{ }^{\circ} \mathrm{C}$ and can be associated with water loss of the $\mathrm{BC}$ surface; the second one, observed with maxima temperature at $374{ }^{\circ} \mathrm{C}$, is attributed to $\mathrm{BC}$ pyrolysis ${ }^{[10]}$. TG curve for PCL (Figure $4 \mathrm{~b}$ ) shows only one weight loss event starting at around $260{ }^{\circ} \mathrm{C}$ up to $490{ }^{\circ} \mathrm{C}$, with maxima temperature near to $400{ }^{\circ} \mathrm{C}$. This event occurs due to the thermal decomposition of PCL ${ }^{[15]}$.

The TGA curve for BC/PCL membrane (Figure 4c) presents a thermal behavior close to pure $\mathrm{BC}$ membrane. A small and

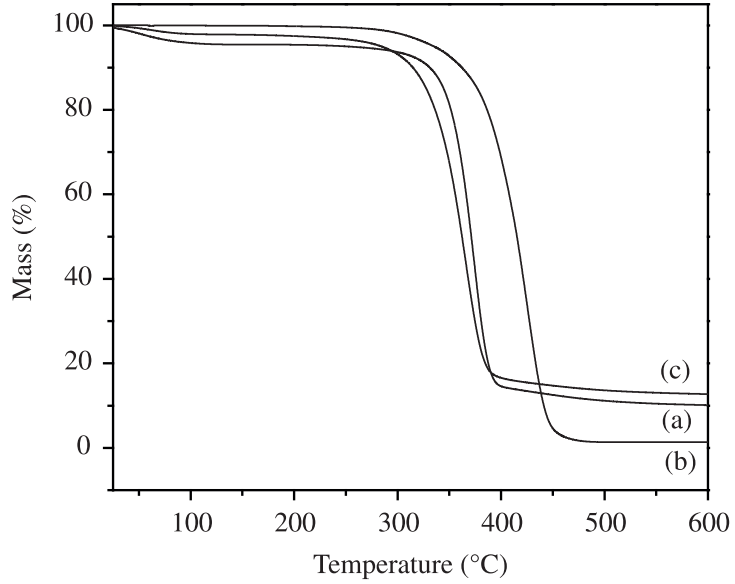

Figure 4. TG curves for: a) BC membrane, b) PCL powder and c) BC/PCL membrane.

continuous mass loss event (around 3\%) is observed from room temperature up to $150{ }^{\circ} \mathrm{C}$. Comparing with pure $\mathrm{BC}$ membrane a slight decrease (around 10 degrees) on thermal degradation of the BC/PCL membrane was observed. Probably, the presence of PCL nanosized particles may be promoting a breakdown in the hydrogen bonds between cellulose chains.

The PCL spherulite-nanosized in the BC/PCL membrane induced a decrease on the tensile strength $(112 \pm 7.0 \mathrm{MPa})$ and Young's Modulus (3.6 $\pm 0.8 \mathrm{GPa})$ as compared a pure BC membrane, tensile strength $(124 \pm 8.1 \mathrm{MPa})$ and Young's Modulus $(16.4 \pm 2.3 \mathrm{GPa})$. In the same way, it was observed an increase on the elongation at break for BC/PCL $(5.4 \pm 0.5 \mathrm{GPa})$ as compared with the pure BC membrane $(1.1 \pm 0.3 \mathrm{GPa})$. The PCL spherulite-nanosized could increase the mobility of the cellulose chains, acting as a plasticizer for $\mathrm{BC}$ membrane. The increase in this property is an important feature for preparation of fully biocompatible flexible display and biodegradable food packaging.

\section{Conclusions}

Novel optically transparent membrane based on bacterial cellulose (BC) and polycaprolactone (PCL) has been prepared by impregnation of PCL acetone solution into dried BC membrane. UV-Vis measurements showed an increase on transparency in $\mathrm{BC} / \mathrm{PCL}$ membrane when compared to pristine BC membrane. The good transparency quality of the biocomposites can be associated with the presence of $\mathrm{BC}$ nanofibers, and principally due to the deposited of PCL nano-sized spherulites which are smaller than wavelength of visible range.

\section{Acknowledgements}

The authors acknowledge Brazilian agencies CNPq, CAPES, FAPESP, FAPERGS, PRONEX/FAPERGS/CNPq and FINEP for financial support. We would like to thank the LMA-IQ for FEG-SEM facilities

\section{References}

1. Nakagaito, A. N.; Nogi, M. \& Yano, H. - MRS Bull., 35, p.214 (2010). http://dx.doi.org/10.1557/mrs2010.654

2. Nogi, M. \& Yano, H. - Adv. Mater., 20, p.1849 (2008). http://dx.doi. org/10.1002/adma.200702559

3. Ummartyotin, S.; Juntaro, J.; Sain, M. \& Manuspiy, H. - Ind. Crop. Prod., 35, p.92 (2012). 
4. Legnani, C.; Vilani, C.; Calil, V. L.; Barud, H. S.; Quirino, W. G.; Achete, C. A.; Ribeiro, S. J. L. \& Cremona, M. - Thin Solid Films., 517, p.1016-1020 (2008). http://dx.doi.org/10.1016/j.tsf.2008.06.011

5. Nogi, M.; Handa, K.; Nakagaito, A. N. \& Yano, H. - Appl. Phys. Lett., 87, p.243110 (2005). http://dx.doi.org/10.1063/1.2146056

6. Shah, J. \& Brown Junior, R. M. - Appl. Microbiol. Biotechnol., 66, p.352 (2005). PMid:15538556. http://dx.doi.org/10.1007/s00253-004$1756-6$

7. Gardner, D. J.; Oporto, G. S.; Mills, R. \& Azizi Samir, M. A. S. - J. Adhes. Sci. Tech.. 22, p.545 (2008). http://dx.doi. org/10.1163/156856108X295509

8. Kim, Y.; Jung, R.; Kim, H. S. \& Jin, H. J. - Curr. Appl. Phys., 70, p.1148 (2008).

9. Fernandes, S. C. M.; Oliveira, L.; Freire, C. S. R.; Silvestre, A. J. D.; Pascoal Neto, C.; Gandini, A. \& Desbriéres, J. - Green. Chem., 11, p.2023 (2009). http://dx.doi.org/10.1039/b919112g

10. Zhijiang, C. \& Guang, Y. - Mater. Lett., 65, p.182 (2011). http://dx.doi. org/10.1016/j.matlet.2010.09.055
11. Gea, S.; Bilotti, E.; Reynolds, C. T.; Soykeabkeaw, N. \& Peijs, T. - Mater. Lett., 64, p.901 (2010). http://dx.doi.org/10.1016/j. matlet.2010.01.042

12. Labet, M. \& Thielemans, W. - Chem. Soc. Rev., 38, p.3484 (2009). PMid:20449064. http://dx.doi.org/10.1039/b820162p

13. Caiut, J. M. A.; Barud, H. S.; Santos, M. V.; Menezes, J.; Messaddeq, Y. \& Ribeiro, S. J. L. - Proceedings SPIE., 8104, p.81040Z-1 (2011). http://dx.doi.org/10.1117/12.895418

14. Wada, M. \& Okano, T. - Cellulose, 8, p.183 (2001). http://dx.doi. org/10.1023/A:1013196220602

15. Machado, A. V.; Botelho, G.; Silva, M. M.; Neves, I. C. \& Fonseca, A. M. - J. Polym. Res., 18, p.1743 (2011). http://dx.doi.org/10.1007/ s10965-011-9580-z
Enviado: 05/04/12

Reenviado: $17 / 07 / 12$

Aceito: 18/07/12 